\title{
Annealing effects on the interfacial properties of GaN MOS prepared by photo-enhanced wet oxidation
}

\author{
H.-M. Wu, J.-Y. Lin, and L.-H. Peng \\ Department of Electrical Engineering and Institute of Electro-optical Engineering \\ National Taiwan University, Taipei, Taiwan, R.O.C. \\ C.-M. Lee and J.-I. Chyi \\ Department of Electrical Engineering, National Central University \\ Chung-Li, Taiwan, R.O.C. \\ E. Chen \\ Tekcore Co. Ltd., Nantou, Taiwan, R.O.C.
}

\begin{abstract}
We investigate the annealing effects on the interfacial properties of gallium oxide $\left(\mathrm{Ga}_{2} \mathrm{O}_{3}\right)$ grown on gallium nitride $(\mathrm{GaN})$ by the photo-enhanced wet oxidation technique. The depth profile resolved XPS analysis indicates an interfacial layer as thin as $20 \mathrm{~nm}$ can be maintained at the $\mathrm{Ga}_{2} \mathrm{O}_{3} / \mathrm{GaN}$ interface when subject to a rapid thermal annealing in an oxygen ambient at $800^{\circ} \mathrm{C}$. Our $\mathrm{I}-\mathrm{V}$ and $\mathrm{C}-\mathrm{V}$ analysis on the MOS device reveals a low interfacial density of state $\sim 5 \times 10^{10} \mathrm{~cm}^{-2} \mathrm{eV}^{-1}$ and high breakdown field above $3 \mathrm{MV} / \mathrm{cm}$. These results suggest the photo-grown $\mathrm{Ga}_{2} \mathrm{O}_{3}$ with post $\mathrm{O}_{2}$ annealing is suitable for power device application.
\end{abstract}

Gallium nitride $(\mathrm{GaN})$ has been regarded as an excellent material for power device application in the high frequency regime [1]. Unfortunately, the lack of high-quality gate insulator has limited the performance of $\mathrm{GaN}$-based transistors. Capacitance analysis on a $\mathrm{GaN}$ metal-insulating-semiconductor (MIS) structure using conventional or novel gate dielectrics such as $\mathrm{SiO}_{2}$ [2], $\mathrm{Si}_{3} \mathrm{~N}_{3}$ [3], $\mathrm{MgO}$ [4], and $\mathrm{Ga}_{2} \mathrm{O}_{3}\left(\mathrm{Gd}_{2} \mathrm{O}_{3}\right)$ [5], only reveal an unsatisfactory minimum interfacial density of state $\left(\mathrm{D}_{\mathrm{it}}\right)$ high above $10^{11} \mathrm{~cm}^{-2} \mathrm{eV}^{-1}$, except a recent work by jet-vapor deposition of $\mathrm{Si}_{3} \mathrm{~N}_{3} / \mathrm{SiO}_{2}$ stacks [6] on $\mathrm{GaN}$ showing a low $D_{\text {it }}$ of $\sim 5 \times 10^{10} \mathrm{~cm}^{-2} \mathrm{eV}^{-1}$

Here, we report the annealing effects on $\mathrm{Ga}_{2} \mathrm{O}_{3} / \mathrm{GaN}$ MOS device structure that was prepared by the photo-enhanced wet oxidation technique [7]. The interfacial and electrical properties were characterized by the $x$-ray photo-emission spectroscopy (XPS), high frequency capacitance-voltage (C-V) and current-voltage (I-V) analysis, respectively. Our results indicate a low $\mathrm{D}_{\text {it }}$ on the order $5 \times 10^{10}$ $\mathrm{cm}^{-2} \mathrm{eV}^{-1}$ and high breakdown field strength $\left(\mathrm{E}_{\mathrm{BD}}\right.$ ) above $3 \mathrm{MV} / \mathrm{cm}$ can be found with $\mathrm{Ga}_{2} \mathrm{O}_{3} / \mathrm{GaN}$ that undergoes a rapid thermal annealing (RTA). in an $\mathrm{O}_{2}$ ambient at $800^{\circ} \mathrm{C}$ to transform the photo-grown $\mathrm{Ga}_{2} \mathrm{O}_{3}$ into a crystalline format.

The GaN film used in this study were epitaxially grown on sapphire substrates by metal-organic chemical vapor deposition and had an unintentional background doping about $\sim 10^{i 7} \mathrm{~cm}^{-3}$. The as-grown samples were first chemically cleaned and etched off a $50 \mathrm{~nm}$ sacrificial GaN surface layer prior to initiate the photo-oxidation process. No external voltage was supplied to the oxidation apparatus in this study. Study of the annealing effects was conducted by placing the photo-oxide films in the following conditions of (1) $400^{\circ} \mathrm{C}$ annealing for one hour in a nitrogen $\left(\mathrm{N}_{2}\right)$ ambient gas, (2) with additional RTA at $800^{\circ} \mathrm{C}$ for $3 \mathrm{~min}$, and (3) similar to (2) but in $\mathrm{O}_{2}$ ambient gas. The $\mathrm{Ga}_{2} \mathrm{O}_{3} / \mathrm{GaN}$ MOS devices thus prepared were shown to have an oxide thickness of $180 \mathrm{~nm}, 50 \mathrm{~nm}$, and $100 \mathrm{~nm}$, respectively We confirm the formation of monoclinic $\beta-\mathrm{Ga}_{2} \mathrm{O}_{3}$ by $\mathrm{x}$-ray diffraction analysis in samples undergone a RTA treatment at $800^{\circ} \mathrm{C}$. The latter process will be shown in the following to play a crucial role in reducing the interfacial defect density, in particular subject to the $\mathrm{O}_{2}$ ambient treatment, and to reduce the leakage current density and improve the forward breakdown field strength.

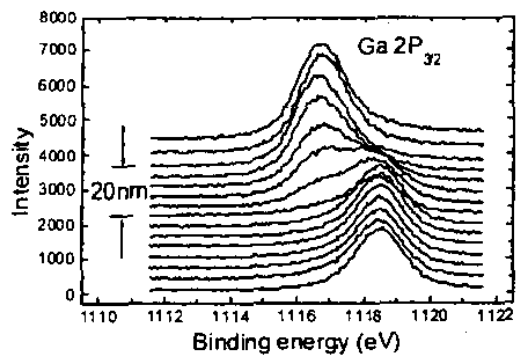

Fig. I The depth profile of XPS measurements on an $\mathrm{O}_{2}$-annealed $\mathrm{Ga}_{2} \mathrm{O}_{2} / \mathrm{GaN}$ sample

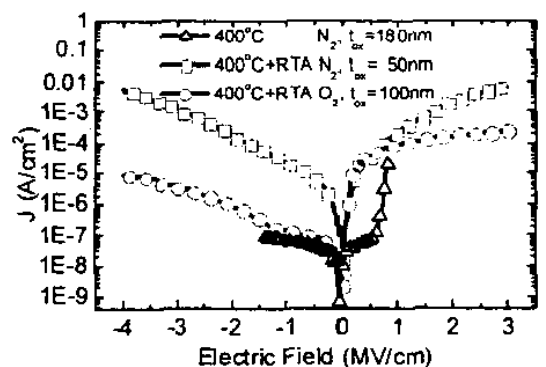

Fig.2 Dependence of leakage current density J on the applied electric field strength E. RTA at $800^{\circ} \mathrm{C}$ 
Student paper

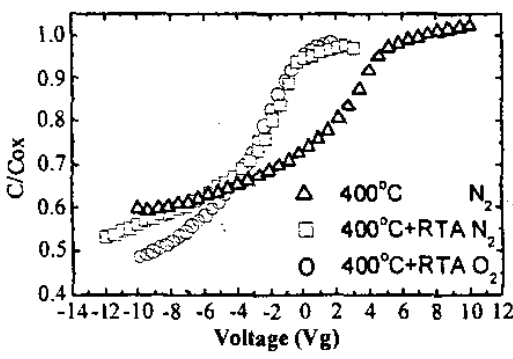

Fig. $3 \mathrm{C}-\mathrm{V}$ characteristics measured at $1 \mathrm{M} \mathrm{Hz}$ and room temperature

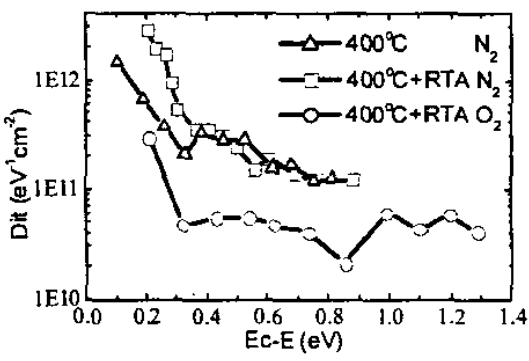

Fig. 4 The interfacial density of state calculated by Terman's method.

First shown in Fig.1 is the depth profile resolved XPS data on the $\mathrm{O}_{2}$ annealed sample. Note the characteristic shift of the gallium $2 \mathrm{P}_{3 / 2}$ binding energy from the $\mathrm{Ga}_{2} \mathrm{O}_{3}$ surface to $\mathrm{GaN}$. Unlike a recent report of thermally oxidized $\mathrm{Ga}_{2} \mathrm{O}_{3}$ showing a diffusion-limited mechanism that can introduce an interfacial layer of $\mathrm{Ga}(\mathrm{ON})$ that is at least $100 \mathrm{~nm}$ wide across the $\mathrm{Ga}_{2} \mathrm{O}_{3} / \mathrm{GaN}$ interface [8], our chemical sensitive data analysis of Fig. 1 reveals a sharp interface whose thickness is less than $20 \mathrm{~nm}$.

We illustrate in Fig.2 the measured leakage current density of MOS devices prepared by the above annealing process. Note an increase of forward breakdown field $\left(E_{\mathrm{BD}}\right)$ above $3 \mathrm{MV} / \mathrm{cm}$ can be maintained in samples subject to RTA treatment at $800^{\circ} \mathrm{C}$, whereas for sample only received $400^{\circ} \mathrm{C}$ annealing, $E_{B D}$ is only $0.65 \mathrm{MV} / \mathrm{cm}$. Furthermore, we note sample under $\mathrm{O}_{2}$ RTA treatment can have a leakage density at $E_{B D}$ that is one order of magnitude smaller than that under $N_{2}$ RTA treatment. This indicates an optimum thermal treatment without degrading the interfacial and electrical properties of $\mathrm{GaN}$ can be achieved without suffering from the conventional high $\left(1100^{\circ} \mathrm{C}\right)$ temperature process. [9]

Our data analysis in Table I further indicates $\mathrm{Ga}_{2} \mathrm{O}_{3} / \mathrm{GaN}$ MOS without high temperature treatment has the largest flat-band shift as shown in the $\mathrm{CV}$ measurement of Fig. 3 and highest interfacial density of state shown in Fig.4. However, a sharp slope can be seen in the depletion region of samples under RTA treatment at $800^{\circ} \mathrm{C}$ in Fig.3, and a dramatic decrease of $D_{i t}$ down to $5 \times 10^{10} \mathrm{~cm}^{-2} \mathrm{eV}^{-1}$ and hysteresis width of $0.26 \mathrm{~V}$ can be observed in MOS device prepared by $\mathrm{O}_{2}$ annealing.

Table 1: Flatband voltage, leakage density, fixed charge density, and interfacial density of state on the annealing conditions

\begin{tabular}{|c|c|c|c|c|c|}
\hline Sample & $V_{B}(V)$ & $\begin{array}{c}\text { Hysteresis width } \\
\text { (V) }\end{array}$ & Leakage density & $\mathrm{Nf}\left(\mathrm{cm}^{-2}\right)$ & Dit $\left(\mathrm{cm}^{-2} \mathrm{eV}^{-1}\right)$ \\
\hline $400^{\circ} \mathrm{C} \quad \mathrm{N}_{2}$ & 3.39 & 3.02 & $\begin{array}{l}\text { Breakdown at } \\
0.65 \mathrm{MV} / \mathrm{cm}\end{array}$ & $3.5 \times 10^{21}$ & $3 \times 10^{11}$ \\
\hline $400^{\circ} \mathrm{C}+\mathrm{RTA}: \mathrm{N}_{2}$ & -0.97 & 0.64 & $\begin{array}{c}100 \mu \mathrm{A} / \mathrm{cm}^{2} \text { at } \\
0.82 \mathrm{MV} / \mathrm{cm}\end{array}$ & $4.35 \times 10^{10}$ & $1.5 \times 10^{11}$ \\
\hline $400^{\circ} \mathrm{C}+\mathrm{RTA}: \mathrm{O}_{2}$ & -1.42 & 0.26 & $\begin{array}{l}100 \mu \mathrm{A} / \mathrm{cm}^{2} \text { at } \\
1.25 \mathrm{MV} / \mathrm{cm}\end{array}$ & $8.64 \times 10^{10}$ & $5 \times 10^{10}$ \\
\hline
\end{tabular}

In summary, a low $D_{\text {ir }}$ on the order of $10^{10} \mathrm{~cm}^{-2} \mathrm{eV}^{-1}$ and high $\mathrm{E}_{\mathrm{BD}}$ above $3 \mathrm{MV} / \mathrm{cm}$ can be resolved on $\mathrm{Ga}_{2} \mathrm{O}_{3} / \mathrm{GaN}$ MOS with $\mathrm{O}_{2}$ annealing at $800^{\circ} \mathrm{C}$. The improved electrical properties are ascribed to the annihilation of interfacial defects by post annealing and transformation into crystalline $\mathrm{Ga}_{2} \mathrm{O}_{3}$.

Reference:

[1] S. A. Vitusevich, S. V. Danylyuk, N. Klein, M. V. Petrychuk, V. N. Sokolov, V. A. Kochelap, A. E. Belyaev, V. Tilak, J. Smart, A. Vertiatchikh, and L. F. Eastman, "Excess low-frequency noise in AlGaN/GaN-based high-electron-mobilty transistors," Appl. Phys. Lett., vol. 80, pp.2126-2128, 2002.

[2] H. C. Casey; Jr., G G. Fountain, R. G. Alley, B. P. Keller, and S. P. DenBaars, "Low interface trap density for remote plasma deposited $\mathrm{SiO}_{2}$ on n-type GaN," Appl. Phys. Lett., vol. 68, pp.1850-1852, 1996.

[3] R. Nakasaki, T. Hashizume, and H. Hasegawa, "Insulator-GaN interface structures formed by plasma-assisted chemical vapor deposition," Physica E., voi.7, pp. 953-957, 2000.

[4] J.Kim, R. Mehandru, B. Luo, F. Ren, B. P. Gila, A. H. Onsteine, C. R. Abemathy, S. J. Pearton, and Y. Irokawa, "Characteristics of $\mathrm{MgO} / \mathrm{GaN}$ gate-controlled MOS diodes," Appl. Phys. Lett., vol. 80, pp. 4555-4557, 2002.

[5] M. Hong, K. A. Anselm, J. Kwo, H. M. Ng, J. N. Baillargeon, A. R. Kortan, J. P. Mannaerts, A. Y. Cho, C. M. Lee, J. I. Chyi, and T. S. Lay, "Properties of $\mathrm{Ga}_{2} \mathrm{O}_{3}\left(\mathrm{Gd}_{2} \mathrm{O}_{3}\right) / \mathrm{GaN}$ metal-insulator-semiconductor diodes," J. Vac Sci. Technol. $B$ i8, pp. 1453-1456, 2000 .

[6] B. Gaffey, L. J. Guido, X. W. Wang, and T. P. Ma, "High-quality oxide/nitride/oxide gate insulator for GaN MIS structures," IEEE Trans. Electron Devices, vol. 48, pp.458-464, 2001.

[7] L. H. Peng, C. H. Liao, Y. C. Hsu, C. S. Jong, C. N. Huang, J. K. Ho, C. C. Chiu, and C. Y. Chen, "Photoenhanced wet oxidation of gallium nitride," Appl. Phys. Lett., vol 76, pp. 511-513, 2000

[8] Y. Nakano, and T. Jimbo, "Interface properties of thermally oxidized $n-G a N$ metal-oxide semiconductor capaciturs," Appl. Phys. Lett. Vol 82, pp.218-220, 2003.

[9] K. Matocha, R. J. Gutmann, and T. P. Chow, "Effect of annealing on GaN-insulator interfaces characterized by MIS capacitors," IEEE Trans. Electron Devices, vol. 50, pp.1200-1204, 2003. 